\section{GAUSSIAN FUZZY ANALYTIC HIERARCHY PROCESS FOR THE EVALUATION OF BENEFIT, COST, AND RISK ANALYSIS IN THE INDONESIAN OIL AND GAS PROCESSING AREA}

Fermi Dwi Wicaksonoa,b*, Yusri Arshada, Haeryip Sihombinga, Imam Baihaqic

aFaculty of Technology Management and Technopreneurship, Universiti Teknikal Malaysia Melaka, 75300 Malaysia

bManagement of Technology Department, Faculty of Business and Management of Technology, Sepuluh Nopember Institute of Technology, 60264 Indonesia

cDepartment of Business and Management, Sepuluh Nopember Institute of Technology, 60111 Indonesia
Article history

Received

20 February 2019

Received in revised form

8 July 2019

Accepted

9 July 2019

Published online

24 October 2019

*Corresponding author p061820001@student.utem.

edu.my

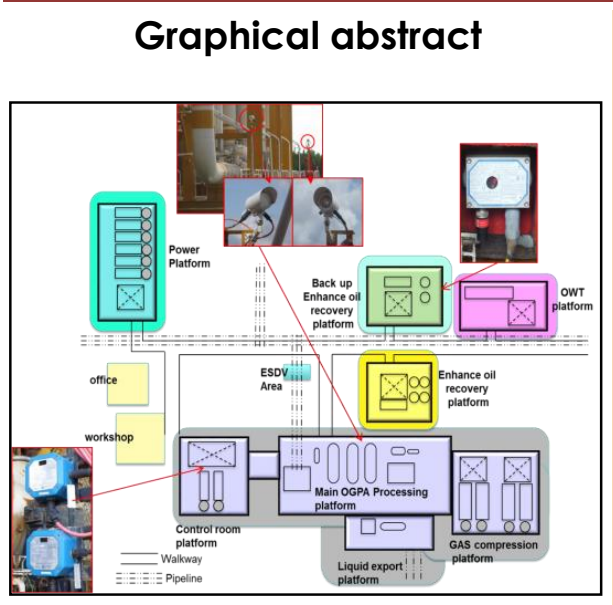

\begin{abstract}
In the oil and gas processing area, adequate risk control should be prearranged to prevent serious accidents, such as major gas leak, fire, and explosion. Installing gas detectors at appropriate technology is one of indispensable conditions for an implementation of risk reduction measures. Open-path infrared and ultrasonic leak gas detector provide wide coverage of gas detection. This capability is advantageous to detect unintentionally gas release in wide coverage and windyclimate processing area. On the other hand, the installation and maintenance cost of those gas detectors are relatively high compared to point infrared and catalytic gas detector. Gaussian fuzzy analytic hierarchy process (Gaussian FAHP) is implemented to evaluate the selection of gas detector technology in terms of benefit, cost and risk criteria. Ten expert panelists from production, safety, and maintenance departments are involved in Delphi Technique to assess the subcriteria of Gaussian FAHP. The Gaussian FAHP evaluation reveals that point infrared gas detector has the highest value among all gas detector technologies. This means that point infrared technology acquires efficient value in delivering service to process safety operation. The obtained result of consistency ratio is always below 0.1 $(C R<0.1)$. By these terms, the Gaussian FAHP is consistent and applicable. By changing $50 \%$ amount of weight in all sub-criteria, there is no alternatives rank position change. The sensitivity analysis proves that the Gaussian FAHP evaluation in the research is consistent irrespectively of the sub-criteria change. The integration of Delphi Technique and Gaussian FAHP in the research is the scientific work to evaluate the best applied detector technology in the oil and gas processing area.

Keywords: Gas detector technology, Delphi technique, Gaussian fuzzy analytic hierarchy process, Sensitivity analysis
\end{abstract}

(C) 2019 Penerbit UTM Press. All rights reserved

\subsection{INTRODUCTION}

Oil and gas business is a high-risk industry following its production of hazardous material. This type of industry mainly deals with flammable liquids, explosive gases, and toxic substances. These materials are intrinsically dangerous especially when there is a potential source of ignition. Fire is the major hazard in the oil and gas 
industry. This hazard could lead to a catastrophic event which causes total loss of the industry. As the fire mostly comes from ignited flammable liquid or explosive gas, there shall be a system to limit uncontrolled hydrocarbon release and source of ignition [1]. Mitigation measures studies should be carried out to overcome the risk occurring in daily process operation, including minimizing the consequences of fire and explosion.

The capability of the system to detect flammable gas release events is a critical component of modern process safety [2]. This safety system is known as gas detector system. Gas detector technology is implemented to identify preliminary gas release for preventing incident escalation. Selection of appropriate gas detector technology is required to ensure effective detection of flammable gas release.

Inappropriate selection of gas detector technology may reduce the reliability of detecting a particular gas release or even yield a sensor completely useless. The evaluation of gas detector selection is intended to ensure its reliability of decreasing catastrophic events probability.

The oil and gas processing area (OGPA) is a petroleum plant in East Kalimantan, Indonesia, which processes oil and gas from hydrocarbon wells and export crude oil to the storage and terminal area. The OGPA produces hydrocarbon gas, crude oil, and hydrocarbon condensate. From the characteristic of the OGPA, major risks identified during operation relate to the design of the facilities. Those are, (1) Major gas leak on gathering network that could impact accommodation camp and office, (2) major gas leak on the OGPA process platform that could impact control room, (3) inadequate fire or gas detection on the main processing platform, gas compression platform, and liquid export platform.

The research objectives are to evaluate and quantify specific value as baseline for the OGPA management to implement gas detector technology. The analyzed criteria cover several aspects, such as benefits delivered by the gas detector, cost required for each gas detector technology, and gas detector latent risk based on the technology used. The result of this research is expected to deliver detail guidance for the OGPA management on which technology is best applied. The comparison result of each gas detector technology is delivered as quantified value, as it can be directly compared and measured.

Delphie technique was firstly intoduced by Dalkey and Helmer [3] as an experimental application to the use of experts. Delphi Technique is a method for obtaining a decision based on expert judgment. It is widely used to solve numerous MCDM problems and commonly participated by panelists or respondents via questinonnaire [4]. Features of Delphi consist of anonymity, iteration and controlled feedback from the prior round to the current one, statistical aggregation of group responses and expert panelists [5], [6]. However, the earlier usage of mere Delphi technique brought several drawbacks due to its necessity to acquire repetitive surveys and the experts' opinion cannot be adequately reflected in quantitatives terms [7]. Therefore several studies proposed the extent usage of Delphi technique by integrating fuzzy multi criteria decision analysis to quantify the relative preferences among criteria. Ouyang and Guo [7] proposed the integrated methodology of intuitionistic fuzzy analytichierarchial process and Delphi technique to evaluate the perspectives of mangroves in municipal waste water treatment. Qiu et al. [8] performed an assessment of water inrush risk by implementing fuzzy-Delphi analytic hierarchy process and grey relational analysis. And Wu et al. [9] implement fuzzy Delphi method (FDM) and fuzzy analytic hierarchy process (FAHP) to analyze the critical influential factors of creativity for college students.

In conventional AHP, the method to perform multicriteria decision making is based on a single crisp number [10]. This method has been criticized for handling uncertainty in the decision maker's judgment where the scale is unbalanced and the evaluation is subjective [11]. Conventional AHP is unable to precisely process uncertainty and vagueness in the evaluation of decision making process [12]. Furthermore, the factors for assessing suitability level of gas detector technology are often observed as qualitative criteria. In this circumstance, the decision making problems may arise from data limitations and ambiguities as a result of incomplete or unreliable data, subjective information, and experts' communication of linguistic preferences [13]. In order to overcome this limitation, several studies have performed the integration of fuzzy logic in the analytic hierarchy process [14], [15]. Developed based on fuzzy set of values and method of multi criteria decision making (MCDM), Fuzzy AHP is capable to identify and represent experts' appraisal of ambiguity when the complex multi-criteria decision-making problems are considered [16]. Based on the advantages delivered by fuzzy AHP, we intend to use the extent application of this approach to evaluate the selection of gas detector technology.

This paper develops an extended Gaussian fuzzy analytic hierarchy process combining with Delphi technique application to solve gas detector technology evaluation in the OGPA. The novelty of this paper elaborates the application of Gaussian fuzzy number to represent uncertainty and vagueness in the pairwise comparison of experts' judgments. As compared with triangular fuzzy number (TFN), Gaussian fuzzy number has more advantages to represent more realistic fuzzy environments and capable to evaluate first fuzzy number which is wrongly weighted as 0 in the TFN [17], [18]. In the final evaluation, we develop center of gravity defuzzification method to represent total significance values for each alternatives technology. This technique is become important because it represent the whole Gaussian membership function, something that simple triangular defuzzification method by average cannot perform. This paper also involves two analyses of consistency. Firstly, the consistency ratio 
method is applied to the defuzzified pairwise comparison matrix. Secondly, the consistency analysis is performed by the sensitivity analysis, a method to detect any change in alternatives rank if there is a change in weight of sub-criteria. An implementation of Gaussian fuzzy number in FAHP was presented by Sahin and Yip [18] to evaluate shipping technology assessment. However, this study had no integration with other MCDM method and did not utilize sensitivity analysis as the consistency check. To the best of our knowledge, the proposed Gaussian FAHP model is the first research methodology which simultaneously integrates Delphi technique and Gaussian fuzzy number, center of gravity defuzzification method, and employs sensitivity analysis as consistency check. The result of Gaussian fuzzy AHP evaluation for gas detector technology selection shall be scientifically true based on this research conclusion.

The organization of this paper remains as follows. Section 1 elaborates the research introduction and background. Section 2 develops the steps to evaluate gas detector technology by using Gaussian FAHP. Section 3 presents the research result and analysis. Finally, Section 4 explains conclusion and future possible improvement.

\subsection{METHODOLOGY}

\subsection{Gas Detector Technology}

There are several types of gas detector technologies used for detecting flammable gas release. Current technologies are catalytic sensor, infrared sensor, and ultrasonic gas leak detector. Catalytic gas sensor detects the presence of a chemical contaminant by an oxidation-reduction reaction with the catalyst [19]. Infrared sensor works by detecting the amount of infrared energy absorbed by a contaminant cloud at specific wavelengths [20]. Infrared sensor possesses a higher unit cost, yet it can often detect hydrocarbon gas more accurately. Ultrasonic gas leak detector senses the noise change which generated by a gas leak and comprises both audible and ultrasonic frequencies [21]. The sensors are able to identify ultrasonic sound frequencies $(25 \mathrm{kHz}$ to $100 \mathrm{kHz}$ ) while excluding audible frequencies (0 $\mathrm{kHz}$ to $25 \mathrm{kHz}$ ) [22].

\subsection{Delphi Technique}

In the process of research development, Delphi Technique is used to determine sub-criteria in selecting the most appropriate gas detector technology. Weighting in form of "Rank-type" [5] is used to specify critical factors which are applicable in selecting gas detector technology. These factors include the benefits, costs, and risk criteria. At first, the Delphi process begins with a problem statement and description of research objectives. Then, experts and panelists are selected based on their competencies in relevant studies and working métier. Number of the reliability of consensus decision is not directly correlated by the number of experts involved [23]. As defined by Chang, [23] six to twelve participants are considered optimal in terms of reliability to perform a Delphi method. We involve ten expert panelists who are competent in chemical-process safety for the research.

\subsection{Triangular Fuzzy Number}

The fuzzy set theory was first introduced by Zadeh [24] by implementing conversion of crisp number into fuzzy number. The membership function in fuzzy set theory within universal set $R$ is defined as follow [25],

$$
\tilde{A}=\left\{\left(x, \mu_{\tilde{A}}(x)\right) \mid x \in R\right\}
$$

Where $\mu_{\tilde{A}}$ is degree of membership of $\mathrm{X}$, which represent universal set $R$ to the interval within $[0,1]$ Membership function of fuzzy set is described as triangle shape curve, known as triangular fuzzy number (TFN)

A fuzzy number on universal set $\mathrm{R}$ to be a TFN is denoted as $\tilde{A}=a_{l}, a_{m}, a_{u}$ with the membership function is equal to [26], [27].

$$
\mu_{\tilde{A}}(x)=\left\{\begin{array}{cr}
0 ; & x<a_{l} \\
\frac{x-a_{l}}{a_{m}-a_{l} ;} & a_{l} \leq x \leq a_{m} \\
\frac{a_{u}-x}{a_{u}-a_{m}} ; & a_{m} \leq x \leq a_{u} \\
0 ; & x>a_{u}
\end{array}\right.
$$

The mathematical operations of triangular fuzzy number include [28], [29]:

Addition,

$$
\begin{aligned}
\tilde{A} \oplus \tilde{B}=\left(a_{l}, a_{m}, a_{u}\right) \oplus\left(b_{l}, b_{m}, b_{u}\right) \\
=\left(a_{l}+b_{l}, a_{m}+b_{m}, a_{u}+b_{u}\right)
\end{aligned}
$$

Subtraction,

$$
\begin{aligned}
\tilde{A} \ominus \tilde{B}=\left(a_{l}, a_{m}, a_{u}\right) \ominus\left(b_{l}, b_{m}, b_{u}\right) & \\
= & \left(a_{l}-b_{l}, a_{m}-b_{m}, a_{u}-b_{u}\right)
\end{aligned}
$$

Multiplication,

$$
\begin{aligned}
\tilde{A} \otimes \tilde{B}=\left(a_{l}, a_{m}, a_{u}\right) \otimes\left(b_{l}, b_{m}, b_{u}\right) & \\
& =\left(a_{l} * b_{l}, a_{m} * b_{m}, a_{u} * b_{u}\right)
\end{aligned}
$$

Division,

$$
\begin{aligned}
\tilde{A} \oslash \tilde{B}=\left(a_{l}, a_{m}, a_{u}\right) \oslash\left(b_{l}, b_{m}, b_{u}\right) \\
=\left(a_{l} / b_{l}, a_{m} / b_{m}, a_{u} / b_{u}\right)
\end{aligned}
$$

And reciprocal,

$$
(\tilde{A})^{-1}=\left(a_{l}, a_{m}, a_{u}\right)^{-1}=\left(\frac{1}{a_{l}}, \frac{1}{a_{m}}, \frac{1}{u}\right)
$$

\subsection{Gaussian Fuzzy Number}

This proposed evaluation is based on the definition of Gaussian membership function which is described as two parameters, i.e. mean/center value $(\mu)$ and 
standard deviation $(\sigma)$. Gaussian distribution function is defined as follows.

$$
\operatorname{Gaussian}(x: \mu, \sigma)=\exp \left[\frac{-(x-\mu)^{2}}{\sigma^{2}}\right]
$$

The value of $\alpha$ in the $Y$ as illustrated in Figure 1 is as follows.

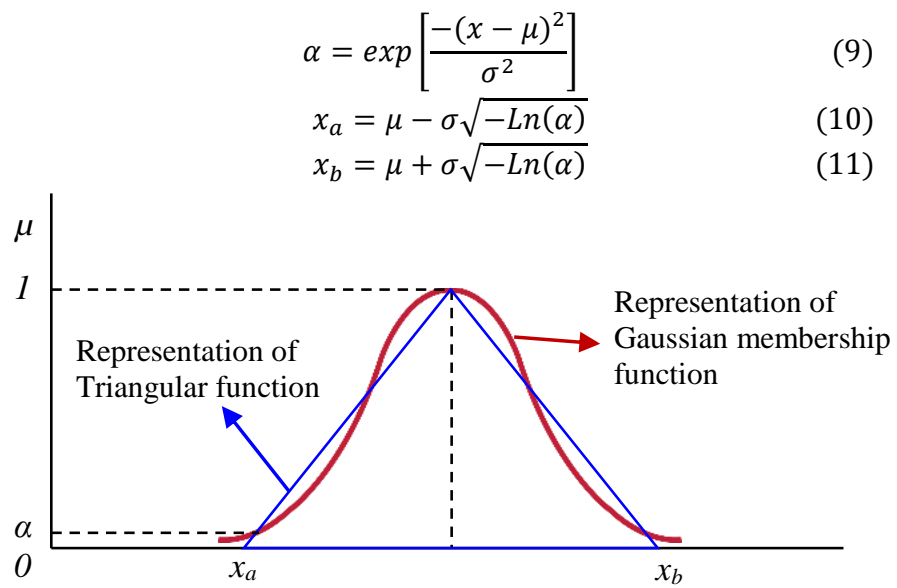

Figure 1 Approximation of Triangular function by the Gaussian membership function

It is notified that the value of Gaussian membership function $\mu$ will reach the asymptote for the value of $y=0$. For the small value of $a$, it will be an approximation for Gaussian membership function $G(x$ : $\mu, \sigma)$ to the Triangular function $T\left(x: x_{a}, x_{b}\right)$. The detailed definition of Gaussian function conversion from the Triangular function is explained by Equation 12 through Equation 21 [17], [18].

Suppose that $T_{i}$ are the triangular fuzzy numbers, they can be converted back to Gaussian to perform computation. And $G_{i}$ are the elements of the preference matrix after performing triangular approximation [17], [18].

$$
T_{i}=\frac{\sum_{j} G_{i j}}{\sum_{i} \sum_{j} G_{i j}}=\frac{\sum_{j}\left(l_{i}{ }^{j}, m_{i}{ }^{j}, u_{i}{ }^{j},\right)}{\sum_{i} \sum_{j}\left(l_{i}{ }^{j}, m_{i}{ }^{j}, u_{i}{ }^{j},\right)}
$$

where $l_{i}{ }^{j} \cong m_{i}{ }^{j}-\sigma_{i}{ }^{j} \sqrt{-\ln (\alpha)}$ and $u_{i}{ }^{j} \cong m_{i}{ }^{j}+\sigma_{i}{ }^{j} \sqrt{-\ln (\alpha)}$

The value of $\alpha$ is set as 0.01 for Triangular function approximation. This means that there is $99 \%$ values are roughly represented by the Gaussian distribution function.

$$
\begin{gathered}
T_{i}=\frac{\left(\sum_{j} l_{i}{ }^{j}, \sum_{j} m_{i}{ }^{j}, \sum_{j} u_{i}{ }^{j}\right)}{\left(\sum_{i} \sum_{j} l_{i}{ }^{j}, \sum_{i} \sum_{j} m_{i}{ }^{j}, \sum_{i} \sum_{j} u_{i}{ }^{j}\right)} \\
=\left(\frac{\sum_{j} l_{i}{ }^{j}}{\sum_{i} \sum_{j} u_{i}{ }^{j}}, \frac{\sum_{j} m_{i}{ }^{j}}{\sum_{i} \sum_{j} m_{i}{ }^{j}}, \frac{\sum_{j} u_{i}{ }^{j}}{\sum_{i} \sum_{j} l_{i}{ }^{j}}\right) \\
\sum_{j} l_{i}{ }^{j}=\sum_{j} m_{i}{ }^{j}-\sum_{j} \sigma_{i}{ }^{j}(\sqrt{-\ln (\alpha)}) \\
\sum_{j}^{j} u_{i}{ }^{j}=\sum_{j}^{j} m_{i}{ }^{j}+\sum_{j}^{j} \sigma_{i}{ }^{j}(\sqrt{-\ln (\alpha)}) \\
\sum_{i} \sum_{j} l_{i}{ }^{j}=\sum_{i} \sum_{j} m_{i}{ }^{j}-\sum_{i} \sum_{j} \sigma_{i}{ }^{j}(\sqrt{-\ln (\alpha)}
\end{gathered}
$$

$$
\sum_{i} \sum_{j} u_{i}{ }^{j}=\sum_{i} \sum_{j} m_{i}{ }^{j}+\sum_{i} \sum_{j} \sigma_{i}^{j}(\sqrt{-\operatorname{Ln}(\alpha)}
$$

Where,

$$
m t_{i}=\frac{\sum_{j} m_{i}{ }^{j}}{\sum_{i} \sum_{j} m_{i}{ }^{j}}, X_{t_{i}}{ }^{L}=\frac{\sum_{j} l_{i}{ }^{j}}{\sum_{i} \sum_{j} u_{i}{ }^{j}}, X_{t_{i}}{ }^{R}=\frac{\sum_{j} u_{i}{ }^{j}}{\sum_{i} \sum_{j} l_{i}{ }^{j}}
$$

Then, $T_{i}$ is converted into asymmetric Gaussian fuzzy number as stated hereunder [17], [18].

$$
\begin{aligned}
\sigma_{t_{i}}{ }^{L} & =\frac{m t_{i}-X_{t_{i}}{ }^{L}}{\sqrt{-\operatorname{Ln}(\sigma)}} \\
\sigma_{t_{i}}{ }^{R} & =\frac{X_{t_{i}}{ }^{R}-m t_{i}}{\sqrt{-\operatorname{Ln}(\sigma)}}
\end{aligned}
$$

Where $\sigma_{t_{i}}{ }^{L}$ and $\sigma_{t_{i}}{ }^{R}$ illustrated the left and the right deviation band of Gaussian fuzzy number.

The membership function of asymmetric Gaussian distribution function is:

$$
\mu_{t_{i}}(x)= \begin{cases}\exp \left[-\left(\frac{x-m_{t_{i}}}{\sigma_{t_{i}}{ }^{2}}\right)\right], & \text { for } x \leq m_{t_{i}} \\ \exp \left[-\left(\frac{x-m_{t_{i}}}{\sigma_{t_{i}}{ }^{2}}\right)\right], & \text { for } x>m_{t_{i}}\end{cases}
$$

As illustrated in Figure 2, two Gaussian fuzzy numbers $\mu_{t_{1}}(x)$ and $\mu_{t_{2}}(x)$ is explained by Equation 22.

$$
\begin{aligned}
& \mu_{t_{1}}(x)= \begin{cases}\exp \left[-\left(\frac{x-m_{t_{1}}}{\sigma_{t_{i}}{ }^{L}}\right)\right], & \text { for } x \leq m_{t_{1}} \\
\exp \left[-\left(\frac{x-m_{t_{1}}}{\sigma_{t_{i}}{ }^{2}}\right)\right], & \text { for } x>m_{t_{1}}\end{cases} \\
& \mu_{t_{2}}(x)= \begin{cases}\exp \left[-\left(\frac{x-m_{t_{2}}}{\sigma_{t_{i}}{ }^{2}}\right)\right], & \text { for } x \leq m_{t_{2}} \\
\exp \left[-\left(\frac{x-m_{t_{2}}}{\sigma_{t_{i}}{ }^{L}}\right)\right], & \text { for } x>m_{t_{2}}\end{cases}
\end{aligned}
$$

The intersection value between $\mu_{t_{1}}(x)$ and $\mu_{t_{2}}(x)$ is written as follows [17], [18].

$$
v=\left\{\begin{array}{l}
\exp \left[-\left(\frac{-\left(m_{t_{2}}-m_{t_{1}}\right)}{\sigma_{t_{1}}{ }^{2}+\sigma_{t_{2}}{ }^{R}}\right)^{2}\right], \text { for } m_{t_{1}}>m_{t_{2}} \\
\exp \left[-\left(\frac{-\left(m_{t_{2}}-m_{t_{1}}\right)}{\sigma_{t_{1}}{ }^{2}+\sigma_{t_{2}}{ }^{2}}\right)^{2}\right], \text { for } m_{t_{1}}<m_{t_{2}}
\end{array}\right.
$$

The level of probability of $T_{2}=\mu_{t_{2}}(x) \geq T_{1}=\mu_{t_{1}}(x)$ is explained as

$$
\begin{aligned}
& V\left(T_{2} \geq T_{1}\right)=h g t\left(T_{1} \cap T_{2}\right)=\mu_{S_{2}}\left(X_{\text {int }}\right) \\
= & \begin{cases}1, & \text { for } m_{t_{2}} \geq m_{t_{1}} \\
\exp \left[-\left(\frac{m_{t_{2}}-m_{t_{1}}}{\sigma_{t_{1}}{ }^{R}+\sigma_{t_{2}}{ }^{2}}\right)\right], & \text { for } m_{t_{2}}<m_{t_{1}}\end{cases}
\end{aligned}
$$

Where $X_{\text {int }}$ is the $x$-coordinate of the intersection point between $\mu_{t_{1}}(x)$ and $\mu_{t_{2}}(x)$. 
$\mathrm{S}_{1}$

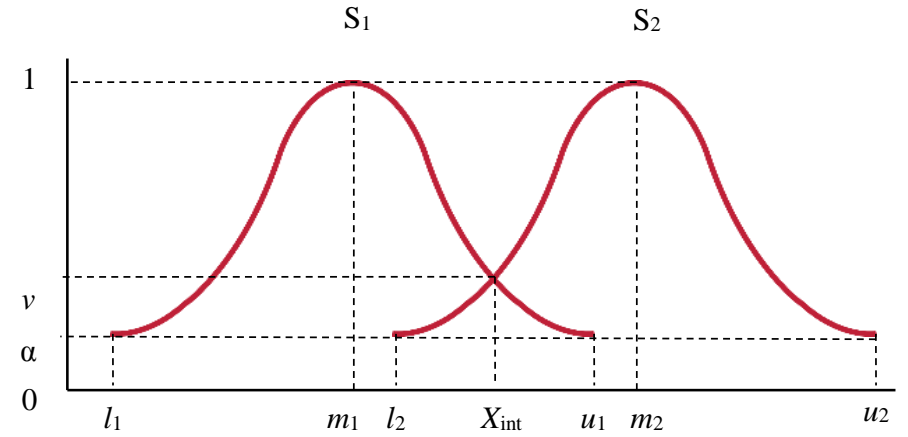

Figure 2 Two Gaussian fuzzy number intersection at the point of $\left(X_{\text {int }}, v\right)$

\subsection{Development of Gaussian FAHP}

The Gaussian fuzzy analytic hierarchy process involves Gaussian fuzzy number as triplet number for computation in a pairwise comparison. The final evaluation is the formed as single crisp number by implementing center of gravity as the defuzzification method. To perform computation in Gaussian FAHP, the procedure is described as follow.

1. Modify triangular fuzzy number into Gaussian fuzzy number, including the linguistic preference variables based on the Saaty scale. The fuzzy membership function is listed as lower and upper value $\left(l_{i}, m_{i}, u_{i}\right)$ as equation below.

$$
\begin{gathered}
\tilde{1}=T\left[x_{a_{1}}, x_{b_{1}}\right]=G\left[x: \mu_{1}, \sigma_{1}\right] ; \\
l_{1}=m_{1}=\mu_{1} \\
m_{1}=\mu_{1} \\
u_{1}=\mu_{1}+3 \sigma_{1} \\
\tilde{3}=T\left[x_{a_{3}}, x_{b_{3}}\right]=G\left[x: \mu_{3}, \sigma_{3}\right] ; \\
l_{3}=\mu_{3}-3 \sigma_{1} \\
m_{3}=\mu_{3} \\
u_{3}=\mu_{3}+3 \sigma_{3} \\
\tilde{5}=T\left[x_{a_{5}}, x_{b_{5}}\right]=G\left[x: \mu_{5}, \sigma_{5}\right] ; \\
l_{5}=\mu_{5}-3 \sigma_{5} \\
m_{5}=\mu_{5} \\
u_{5}=\mu_{5}+3 \sigma_{5} \\
\tilde{7}=T\left[x_{a_{7}}, x_{b_{7}}\right]=G\left[x: \mu_{7}, \sigma_{7}\right] ; \\
l_{7}=\mu_{7}-3 \sigma_{7} \\
m_{7}=\mu_{7} \\
u_{7}=\mu_{7}+3 \sigma_{7} \\
\tilde{9}=T\left[x_{a_{9}}, x_{b_{9}}\right]=G\left[x: \mu_{9}, \sigma_{9}\right] ; \\
l_{9}=\mu_{9}-3 \sigma_{9} \\
m_{9}=\mu_{9} \\
u_{9}=m_{9}=\mu_{9}
\end{gathered}
$$

Where

$$
\begin{aligned}
& x_{a}=\tilde{\mu}_{i}-\tilde{\sigma}_{i} \sqrt{-\operatorname{Ln}(\alpha)} \\
& x_{b}=\tilde{\mu}_{i}+\tilde{\sigma}_{i} \sqrt{-\operatorname{Ln}(\alpha)}
\end{aligned}
$$

and the value of $\alpha$ is chosen as 0.01 to approximate triangular fuzzy number. $\tilde{\mu}_{i}$ are the mean value of Gaussian fuzzy number, it is typically $=m_{i}, \tilde{\sigma}_{i}$ is the standard deviation of the Gaussian fuzzy number, it is obtained by solving Equation 30.

2. Perform computation based on fuzzy pairwise comparison matrix. Develop a fuzzy judgment matrix $\tilde{A}$ based on Gaussian fuzzy number $\left(l_{i}, m_{i}, u_{i}\right)$ which one of criteria is more important to another [30].

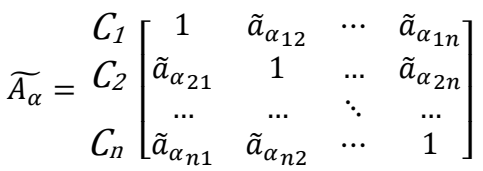

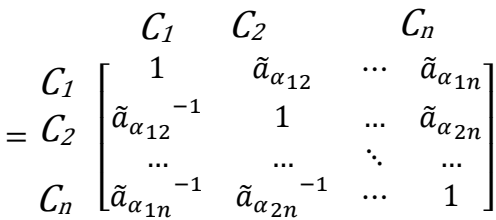

Where $\widetilde{A_{a_{l \jmath}}}$ is the fuzzy pairwise comparison value $i$ compare to $j,\left(l_{i}, m_{i}, u_{i}\right)$ are the lower value, middle value, and the upper value properties of the fuzzy pair wise comparison matrices $\widetilde{A_{a_{\imath} \jmath^{\prime}}}$

3. Calculate fuzzy weight by applying geometric mean for each criterion. As stated by Wang et al. [30], the fuzzy weight of each criterion is calculated as follows,

$$
\begin{gathered}
l_{n}=\left[\prod_{j=1}^{n} l_{i j}\right]^{\frac{1}{n}} ; m_{n}=\left[\prod_{j=1}^{n} m_{i j}\right]^{\frac{1}{n}} ; \\
u_{n}=\left[\prod_{j=1}^{n} u_{i j}\right]^{\frac{1}{n}}
\end{gathered}
$$

4. Determine the rank for each alternative by implementing defuzzification of Gaussian fuzzy number $\left(l_{n}, m_{n}, u_{n}\right)$. It is necessary to define a method for building a crisp value from the fuzzy number to choose the optimum alternative. Therefore, a defuzzification process needs to be adopted, which arranges the fuzzy numbers for ranking [30]. The defuzzification of $\left(l_{n}, m_{n}, u_{n}\right)$ is based on center of gravity method of the Gaussian distribution.

$$
\begin{array}{r}
U_{n}{ }^{*}=\frac{\int_{l_{n}}^{u_{n}} x \cdot G\left(x: \tilde{\mu}_{n}, \tilde{\sigma}_{n}\right) d x}{\int_{l_{n}}^{u_{n}} G\left(x: \tilde{\mu}_{n}, \tilde{\sigma}_{n}\right) d x} \\
U_{n}{ }^{*}=\frac{\int_{l_{n}}^{u_{n}} \frac{x}{\sqrt{2 \pi \tilde{\sigma}_{n}^{2}}} e^{-\frac{\left(x-\widetilde{\mu}_{n}\right)^{2}}{2 \widetilde{\sigma}_{n}^{2}}} d x}{\int_{l_{n}}^{u_{n}} \frac{1}{\sqrt{2 \pi \tilde{\sigma}_{n}^{2}}} e^{-\frac{\left(x-\widetilde{\mu}_{n}\right)^{2}}{2 \widetilde{\sigma}_{n}^{2}}} d x}
\end{array}
$$

Where $\tilde{\mu}_{n}$ and $\tilde{\sigma}_{n}$ are the mean value and standard deviation of Gaussian fuzzy number after performed by Geometric mean operation. It is determined that:

$$
\begin{gathered}
\tilde{\mu}_{n}=m_{n} \\
\tilde{\sigma}_{n}=\frac{\tilde{\mu}_{n}-l_{n}}{3} \text { for } m_{n}>l_{n} \text { and } m_{n}=u_{n}
\end{gathered}
$$




$$
\tilde{\sigma}_{n}=\frac{u_{n}-\tilde{\mu}_{n}}{3} \text { for } u_{n}>m_{n} \text { and } m_{n}=l_{n}
$$

5. Perform consistency analysis. As Fuzzy AHP has been defined its crisp value, it is important to check whether the comparison matrix is consistent. The crisp value is then formed into a comparison matrix similar with conventional AHP. The value of defuzzification $U$ is developed into crisp value comparison matrix.

$$
\widetilde{U}_{n}=\left[\begin{array}{cccc}
U_{11} & U_{12} & \cdots & U_{1 n} \\
U_{21} & U_{22} & \cdots & U_{2 n} \\
\cdots & \cdots & \ddots & \cdots \\
U_{n 1} & U_{n 2} & \cdots & U_{n n}
\end{array}\right]
$$

The consistency of crisp matrix $U$ is evaluated by AHP consistency analysis. "When the conventional comparison matrix $U$ is consistent, it means that fuzzy comparison matrix $\widetilde{U}$ is also consistent" [31]. Consistency analysis is then calculated by implementing consistency ratio calculation in AHP method.

In addition, determine weight of fuzzy value by normalizing each criterion.

$$
\begin{gathered}
U_{\text {sum }}=\sum_{i=1}^{n} U_{i} \\
\widetilde{U}_{i j}=\frac{U_{i}}{U_{\text {sum }}} \quad ; \text { for } i=1,2,3, \ldots, n
\end{gathered}
$$

Whre $\widetilde{U}_{i j}$ is the fuzzy weight value of the $i$-th criterion.

6. Determine fuzzy final value by calculating hierarchical layer sequencing [30].

$$
\widetilde{W_{l}}=\sum_{j=1}^{n} \widetilde{U_{l}} * \widetilde{U_{l j}}
$$

Where $\widetilde{U_{l j}}$ is the fuzzy weight value of the $j$-th criteria to the $i$-the alternatives.

\subsection{Research Framework}

The structure of this research is divided into several phases described in Figure 4.

\subsection{RESULT AND DISCUSSION}

This chapter defines the methods implemented in the research. As selecting gas detector technology is the ultimate goal, the methods should comply with systematic research framework

\subsection{Delphi Technique for Developing Research Sub- Criteria and Alternatives}

The implementation of Delphi technique is carried out during November-December 2017 in the Petroleum Company operating the OGPA. At first, Delphi technique is performed by describing problems which is encounter by the OGPA in regards to the selection of gas detector technology. Explanations of recent gas detector characteristic, feature, and working principle are delivered as to the panelists. Then, the questionnaire is developed based on three aspects which are evaluated in selecting gas detector technology. Benefit aspect is first mentioned to the expert panelists. It is selected 5 sub-criteria that best mentioned by the expert panelists. Secondly, cost aspect is mentioned covering sub-criteria for Capital expenditure, maintenance cost, training, and development cost.

Four sub-criteria are selected from the cost aspect. The similar method is performed for risk aspect, and 5 sub-criteria are selected accordingly. The number of sub-criteria is limited to 4-7, due to consideration of bias and consistency. The working groups involved in the Delphi technique are Maintenance-instrument engineer, Head of Production Support Department, Head of Field Operation Safety Method Services, Head of Operating Philosophy Services and Safety Concept, Safety Method engineers, and Process engineers.

Delphi technique is carried out in three-round analysis. In the first and second round, Delphi technique is performed by interviewing the expert panelists. Feedback from the first round is delivered in the second round. By delivering feedback, it is expected that panelists shall respond to a consensus understanding. The first and second round is performed to construct the sub-criteria for selecting the gas detector technology; whereas the third round is specified to weight the defined sub-criteria and the alternatives' attribute. The development of criteria weighting is performed by delivering questionnaire in the third round of Delphi technique. Data of the questionnaire are gathered by providing a pairwise comparison of criteria for selecting gas detector technology. Each of criteria is developed into openended question describing how important a criterion compared to another criterion. The result of Delphi method is mostly reached consensus in the second and third round. The explanation of about what if there is no consensus in pairwise comparison is graphically explained in Figure 3, the Delphi method should be repeated again-and-again, until the consensus is reached.

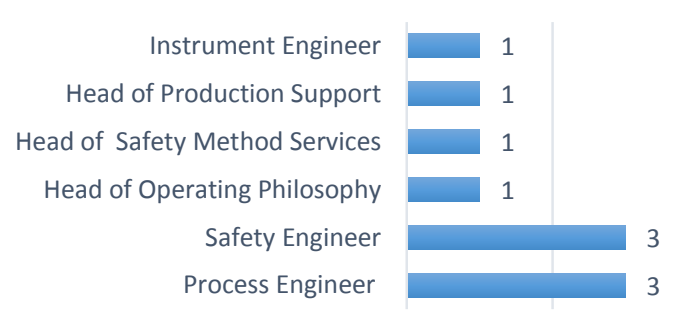

Figure 3 Working position of expert panelists involving in the Delphi technique 


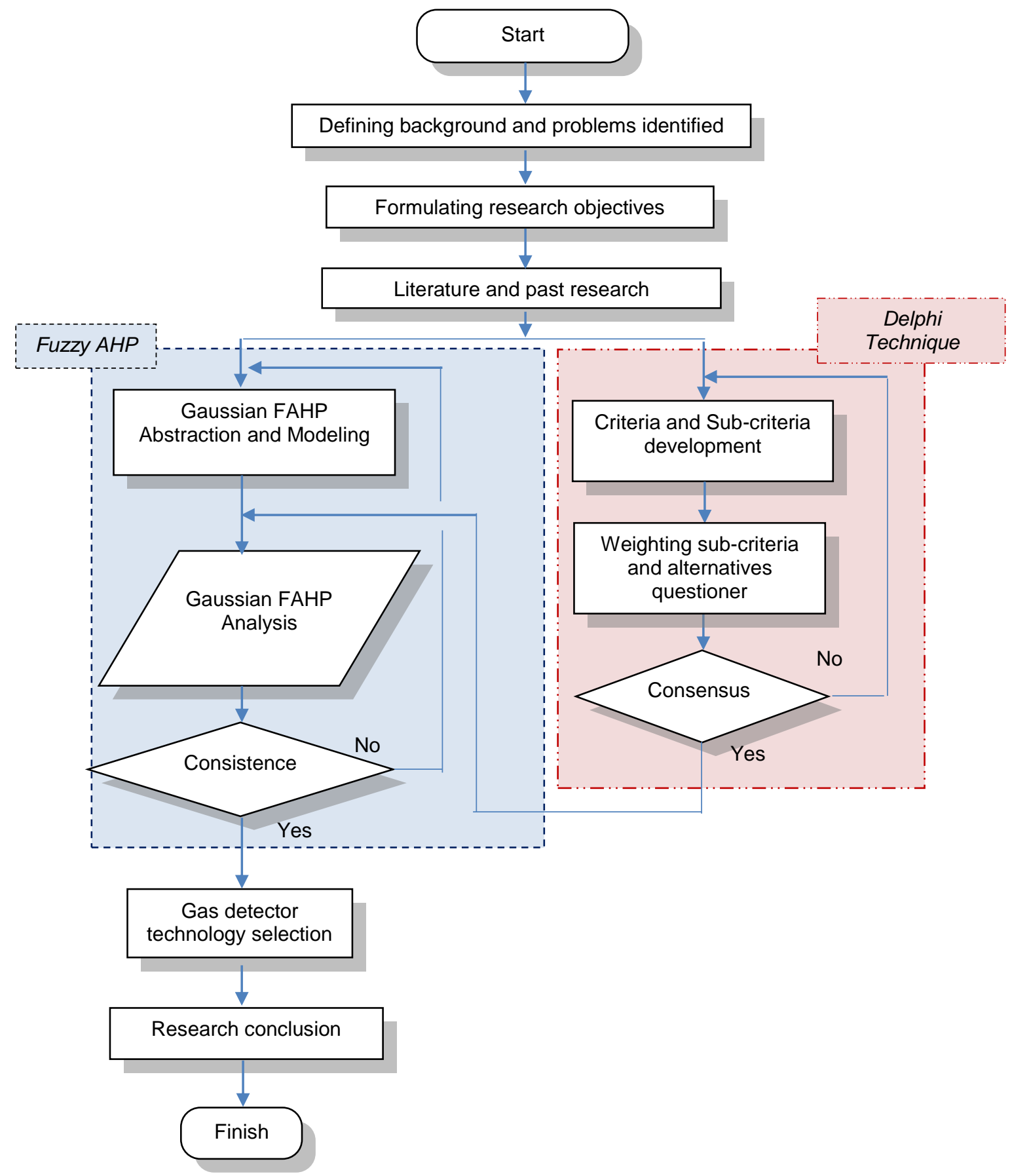


Table 1 Sub-criteria explanation according to Delphi technique consensus

\begin{tabular}{|c|c|c|}
\hline Criteria & Sub-criteria & Description \\
\hline \multirow[t]{5}{*}{$\begin{array}{l}\text { Benefit } \\
\text { (C1) }\end{array}$} & $\begin{array}{l}\text { Reliability and } \\
\text { precision } \\
\text { (C11) }\end{array}$ & $\begin{array}{l}\text { The ability of gas detector } \\
\text { technology to deliver their } \\
\text { intended function. }\end{array}$ \\
\hline & $\begin{array}{l}\text { Detection } \\
\text { coverage } \\
\text { area (C12) }\end{array}$ & $\begin{array}{l}\text { It is linked to the number of gas } \\
\text { detector needed. As wider the } \\
\text { coverage the more gas detectors } \\
\text { are able to protect the wider } \\
\text { hazardous area. }\end{array}$ \\
\hline & $\begin{array}{l}\text { Delivering } \\
\text { continuous } \\
\text { concentration } \\
\text { monitoring } \\
\text { (C13) }\end{array}$ & $\begin{array}{l}\text { The ability to measure flammable } \\
\text { gas concentration and display } \\
\text { such measurement into existing } \\
\text { control panel. }\end{array}$ \\
\hline & $\begin{array}{l}\text { Oxygen } \\
\text { deficiency } \\
\text { resistance } \\
\text { (C14) }\end{array}$ & $\begin{array}{l}\text { The ability of gas detector to work } \\
\text { without sufficient oxygen }\end{array}$ \\
\hline & $\begin{array}{l}\text { Response time } \\
\text { (C15) }\end{array}$ & $\begin{array}{l}\text { Processing time for a gas detector } \\
\text { to detect and deliver output } \\
\text { command. }\end{array}$ \\
\hline \multirow[t]{4}{*}{$\begin{array}{l}\text { Cost } \\
(\mathrm{C} 2)\end{array}$} & $\begin{array}{l}\text { Capital } \\
\text { expenditure of } \\
\text { the } \\
\text { technology } \\
\text { (C21) }\end{array}$ & $\begin{array}{l}\text { Amount of money which is spent } \\
\text { by petroleum company to invest in } \\
\text { the gas detector technology. }\end{array}$ \\
\hline & $\begin{array}{l}\text { Preventive } \\
\text { maintenance } \\
\text { cost (C22) }\end{array}$ & $\begin{array}{l}\text { Man-hour cost required for } \\
\text { maintenance, } \\
\text { maintenance frequency, and } \\
\text { duration of maintenance. }\end{array}$ \\
\hline & $\begin{array}{l}\text { Breakdown } \\
\text { maintenance } \\
\text { cost (C23) }\end{array}$ & $\begin{array}{l}\text { Price spent for un-repairable } \\
\text { damage. }\end{array}$ \\
\hline & $\begin{array}{l}\text { Training and } \\
\text { development } \\
\text { cost (C24) }\end{array}$ & $\begin{array}{l}\text { The training cost includes } \\
\text { investment on operator's training } \\
\text { to master the gas detector } \\
\text { technology. }\end{array}$ \\
\hline \multirow[t]{5}{*}{$\begin{array}{l}\text { Risk } \\
\text { (C3) }\end{array}$} & $\begin{array}{l}\text { Spurious } \\
\text { detection } \\
\text { (C31) }\end{array}$ & $\begin{array}{l}\text { Gas detector often detects false } \\
\text { gas concentration that can lead to } \\
\text { the process shutdown. }\end{array}$ \\
\hline & $\begin{array}{l}\text { Probability } \\
\text { failure } \\
\text { demand } \\
\text { (C32) }\end{array}$ & $\begin{array}{l}\text { Statistics number of failure during } \\
\text { expected demand of an } \\
\text { operation. It is directly linked to the } \\
\text { reliability of the gas detector } \\
\text { system. }\end{array}$ \\
\hline & $\begin{array}{l}\text { Sensor } \\
\text { poisoning } \\
\text { (undetectable } \\
\text { in fatigue } \\
\text { condition) } \\
\text { (C33) }\end{array}$ & $\begin{array}{l}\text { When gas detectors in most of the } \\
\text { time exposed to flammable gas } \\
\text { concentration, there is a possibility } \\
\text { that they do not detect the real } \\
\text { value of gas concentration. }\end{array}$ \\
\hline & $\begin{array}{l}\text { Environment } \\
\text { distractive } \\
\text { signal (C34) }\end{array}$ & $\begin{array}{l}\text { Vulnerability due to environment } \\
\text { signal such as, noise, fog, and } \\
\text { vibration. }\end{array}$ \\
\hline & $\begin{array}{l}\text { Immaturity of } \\
\text { technology } \\
\text { (C35) }\end{array}$ & $\begin{array}{l}\text { In-compatibility of gas detector } \\
\text { technology to the existing process } \\
\text { facilities. }\end{array}$ \\
\hline
\end{tabular}

\subsection{Gaussian Fuzzy Analytic Hierarchy Process Evaluation}

By evaluating the characteristic of each gas detector technology, Gaussian fuzzy AHP method is implemented to select the gas detector technology based on their benefit, cost and risk analysis. The Benefit, Cost, and Risk criteria are broken down into a set of a hierarchy structure. Based on Equation 25 trough Equation 29, conversion of crisp AHP number into triplet fuzzy AHP number is performed.

Table 2 Sub-criteria explanation according to Delphi technique consensus

\begin{tabular}{cccc}
$\begin{array}{c}\text { Saaty } \\
\text { scale }\end{array}$ & $\begin{array}{c}\text { Triangular } \\
\text { fuzzy } \\
\text { number }\end{array}$ & $\begin{array}{c}\text { Linguistic } \\
\text { preference } \\
\text { scale }\end{array}$ & $\begin{array}{c}\text { Gaussian } \\
\text { fuzzy number }\end{array}$ \\
\hline 1 & $\mathrm{~T}(1,1,3)$ & $\begin{array}{c}\text { Equally important } \\
\text { Weakly important }\end{array}$ & $\mathrm{G}(\mathrm{x}: 1,0.932)$ \\
3 & $\mathrm{~T}(1,3,5)$ & $\begin{array}{c}\text { Wea.932) } \\
\text { Essentially }\end{array}$ & $\mathrm{G}(\mathrm{x}: 5,0.932)$ \\
5 & $\mathrm{~T}(3,5,7)$ & $\begin{array}{c}\text { important } \\
\text { Very strong } \\
\text { important }\end{array}$ & $\mathrm{G}(\mathrm{x}: 7,0.932)$ \\
7 & $\mathrm{~T}(5,7,9)$ & $\begin{array}{c}\text { Absolutely } \\
\text { important }\end{array}$ & $\mathrm{G}(\mathrm{x}: 9,0.932)$ \\
9 & $\mathrm{~T}(7,9,9)$ & & \\
\hline
\end{tabular}

We develop fuzzy judgment matrix $\tilde{A}$ based on Gaussian fuzzy number $\left(l_{i}, m_{i}, u_{i}\right)$ which one of criteria is more important to another. The value of pairwise comparison is obtained based on Delphi technique round-3 consensus. All pairwise comparison matrix in following computation are consistence $(C R<0.1)$. Due to space limitation, detail calculation of $\mathrm{CR}$ will not be displayed.

\subsubsection{Fuzzy Weight of Sub-Criteria and Alternatives}

Based on the fuzzy pairwise comparison matrix for each sub-criteria and alternatives, the fuzzy weight value is calculated by Equation 38. The calculation results of geometric mean are then calculated by Equation 32 to obtain the fuzzy weight values. These fuzzy weight values are still in triplet number. Therefore, defuzzification process is implemented to convert the fuzzy weight values to a crisp number. The calculation results of the fuzzy weight values are described in Table 3.

Table 3 The fuzzy weight values for the sub-criteria

\begin{tabular}{cccc}
\hline & Fuzzy Weight & $\begin{array}{c}\text { Standard } \\
\text { deviation }\end{array}$ & $\begin{array}{c}\text { Defuzzified } \\
\text { Weight }\end{array}$ \\
\hline Benefit & & & \\
\hline C11 & $(1.438,3.680,5.014)$ & 0.445 & 3.678 \\
C12 & $(0.497,1.838,4.381)$ & 0.847 & 3.379 \\
C13 & $(0.340,0.725,2.177)$ & 0.484 & 0.901 \\
C14 & $(0.260,0.725,1.667)$ & 0.314 & 0.768 \\
C15 & $(0.202,0.281,0.984)$ & 0.234 & 0.420 \\
\hline Cost & & & \\
\hline C21 & $(1.173,3.201,4.587)$ & 0.462 & 3.199 \\
C22 & $(0.433,1.000,3.223)$ & 0.741 & 1.280 \\
C23 & $(0.429,0.669,1.146)$ & 0.159 & 0.690 \\
C24 & $(0.261,0.467,1.039)$ & 0.191 & 0.516 \\
\hline Risk & & & \\
\hline C31 & $(1.676,3.936,5.249)$ & 0.437 & 3.934 \\
C32 & $(0.827,2.036,4.570)$ & 0.845 & 2.163 \\
C33 & $(0.340,0.903,2.301)$ & 0.466 & 1.002 \\
C34 & $(0.296,0.394,1.097)$ & 0.234 & 0.522 \\
C35 & $(0.242,0.351,0.491)$ & 0.047 & 0.352 \\
\hline
\end{tabular}




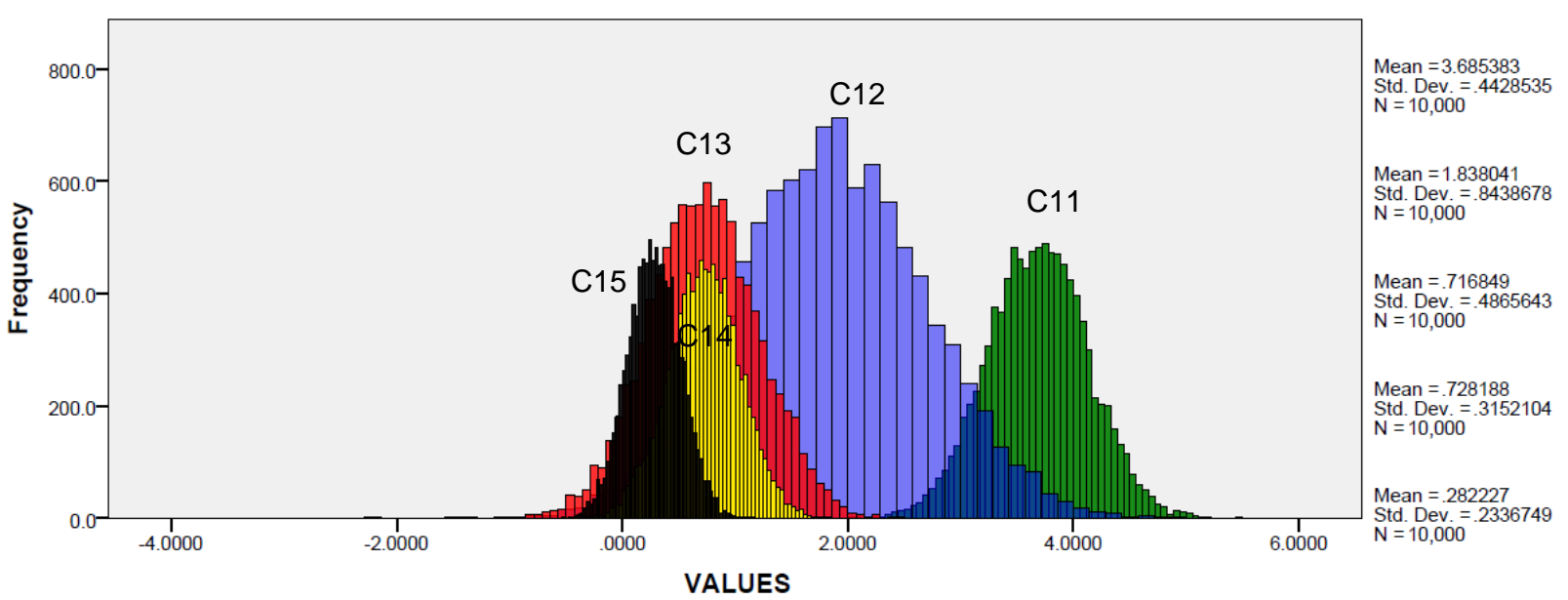

Figure 5 Gaussian distribution plot of criteria in accordance to benefit category as expressed by Gaussian probability density function

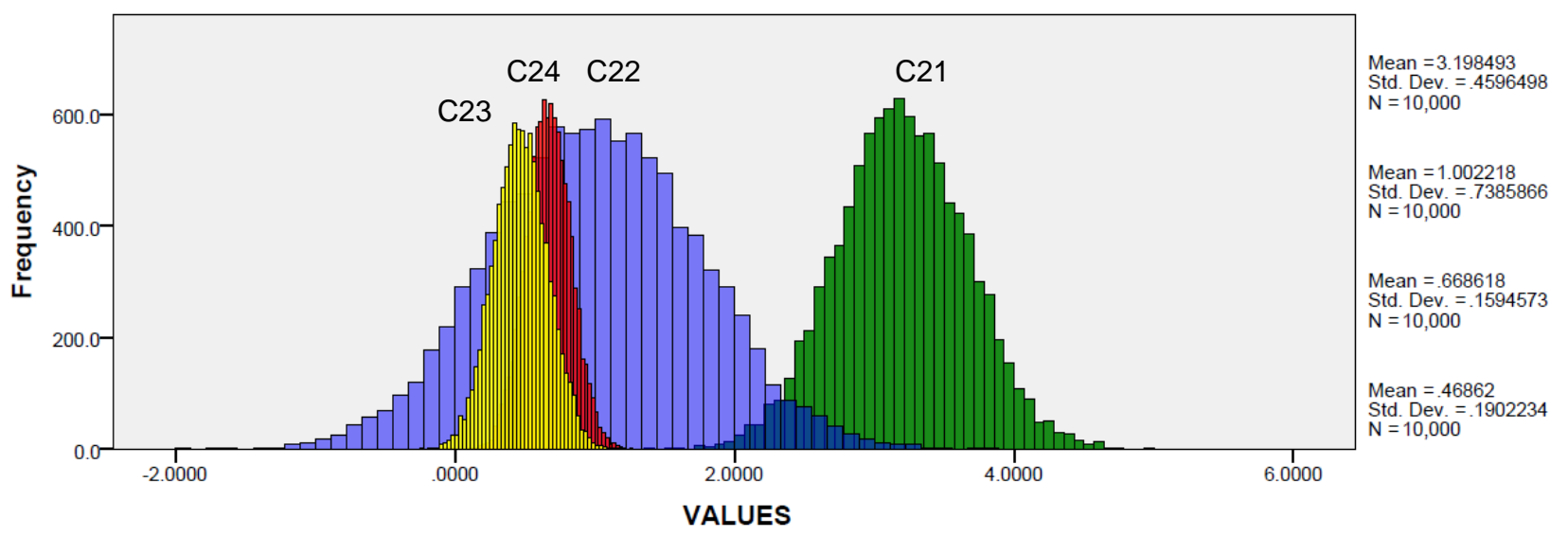

Figure 6 Gaussian distribution plot of criteria in accordance to cost category as expressed by Gaussian probability density function

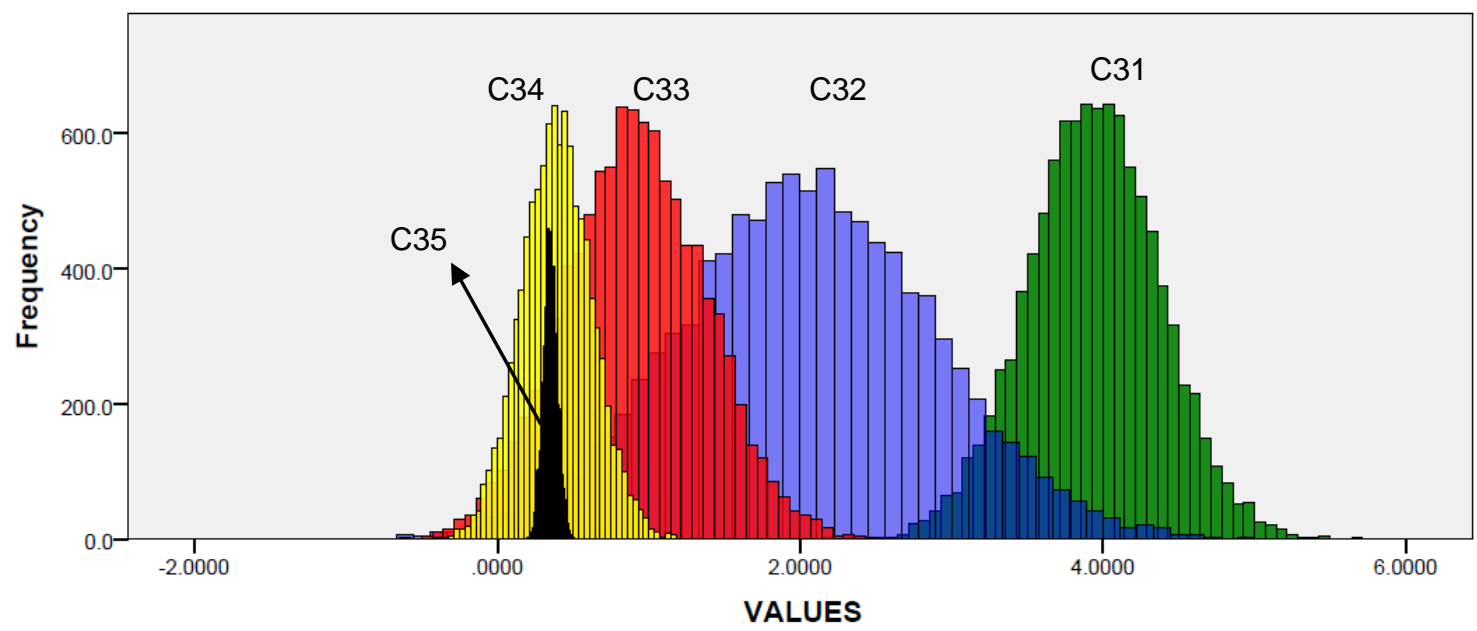

Mean $=3.936978$ Std. Dev. $=.440697$ $\mathrm{N}=10,000$

Mean $=2.036866$ Std. Dev. $=.8466744$
$\mathrm{~N}=10,000$

Mean $=.911384$ Std. Dev. $=.4624904$ $\mathrm{N}=10,000$

Mean $=.391998$ Std. Dev. $=.2326704$ $\mathrm{N}=10,000$

Mean $=.350476$ Std. Dev. $=.0468869$ VALUES

Figure 7 Gaussian distribution plot of criteria in accordance to risk category as expressed by Gaussian probability density function 


\subsubsection{Fuzzy Weight of Sub-Criteria and Alternatives}

In order to obtain the fuzzy final values, fuzzy hierarchical layer sequencing should be calculated. By implementing Equation 39 the final fuzzy values for each alternative is determined. According to Jing et al. [30] the fuzzy hierarchical layer sequencing can be expressed as:

$$
\begin{aligned}
\widetilde{U}_{l}= & \left(\left(\widetilde{w_{1}} \otimes \widetilde{w_{12}}\right) \oplus\left(\widetilde{w_{2}} \otimes \widetilde{w_{22}}\right) \oplus \ldots \oplus\left(\widetilde{w_{J}} \otimes \widetilde{r_{J}}\right)\right) \\
& \varnothing\left(\widetilde{w_{1}} \oplus \widetilde{w_{2}} \oplus \ldots \oplus \widetilde{w_{J}}\right)
\end{aligned}
$$

By implementing Equation 40, the defuzzified final values of alternatives are obtained. The calculation result is described in Table 4.

Table 4 Fuzzy hierarchical layer sequencing for each alternative in regards to sub-criteria

\section{Benefit category}

\begin{tabular}{cc}
\hline Alternatives & $\begin{array}{c}\text { Final Calculation } \\
\text { Value }\end{array}$ \\
\hline A1 & 0.1244 \\
A2 & 0.2242 \\
A3 & 0.3056 \\
A4 & 0.2998 \\
\hline
\end{tabular}

\section{Cost category}

\begin{tabular}{cc}
\hline Alternatives & $\begin{array}{c}\text { Final Calculation } \\
\text { Value }\end{array}$ \\
A1 & 0.1585 \\
A2 & 0.2558 \\
A3 & 0.1843 \\
A4 & 0.4015 \\
\hline
\end{tabular}

Risk category

Alternatives

\begin{tabular}{cc}
\hline Alternatives & $\begin{array}{c}\text { Final Calculation } \\
\text { Value }\end{array}$ \\
A1 & 0.1654 \\
A2 & 0.2815 \\
A3 & 0.0574 \\
A4 & 0.4516 \\
\hline
\end{tabular}

The fuzzy final values are obtained for each level of criteria, sub-criteria, and alternatives. Specifically, for Risk criteria, language preference is necessary to be predefined. In correspondence to the risk criteria, the risk is quantified as:

$$
\begin{aligned}
& r \leq 0.1 \quad, \quad \text { Acceptable } \\
& 0.1<r \leq 0.5, \quad \text { Tolerable } \\
& r>0.5 \quad \text { Unacceptable }
\end{aligned}
$$

Where $r$ is the fuzzy final value for risk criteria. The final results of Gaussian FAHP analysis are listed in Table 5.

As a comparison, we calculate the weight of each alternative by conventional AHP method. The results of this comparison is derscribed in Figure 8 until Figure 10. In general, the results of Gaussian FAHP and conventional AHP are quite similar. The ranking of sub-criteria and alternatives between Gaussian FAHP and conventional AHP are quite similar. Conventional AHP shows that all consistency ratio below 0.1. On the other hand, consistency ratio of Gaussian FAHP is calculated by transforming the fuzzy pairwise comparison matrix to crisp number matrix through defuzzification process. It is confirmed that all the defuzzified pairwise comparison matrices are consistent.

Although Defuzzified values of final alternatives weight are quite similar to conventional AHP, it does not mean that the proposed Gaussian FAHP brings similar performance to conventional AHP. The intention to demonstrate the comparison between two methods is to convince the correct alternatives ranking arrangement. This means that the ranking arrangement of criteria and alternatives ara valid according to the conventional AHP and proposed Gaussian FAHP. This circumstance is important in order to cross-check the methodology computation and evaluation.

This paper clearly demontrates that Gaussian FAHP is capable of handling uncertainty comes from the linguistic preference of experts' judgments, something that conventional AHP cannot evaluate. For example, we can see in Table 3, the evaluation of criteria according to category is performed based on interval value which follows Gaussian distribution of $G(x: \mu, \sigma)$ or minimum value $=\mu-3 \sigma$, most probable value $=\mu$, and upper value $=\mu+3 \sigma$. This computation is able to evaluate numerous pairwise judgments within interval $[\mu-3 \sigma$ and $\mu+3 \sigma]$. Based on this terminology, it can be inferred that the pairwise comparison is still valid in spite of the consensus in determining criteria value is not reached as long as the value of judgments lies within $[\mu-3 \sigma$ and $\mu+3 \sigma]$. Figure 5 - Figure 7 express the Gaussian probability density function with 10,000 random variables following the mean value and standard deviation. Therefore, any kind of random judgments corresponding to the criteria remains valid within the interval values, and it is explained how the Gaussian FAHP posess better performence in handling uncertainty and vagueness.

Table 5 The result of benefit and cost ratio of fuzzy AHP in accordance with associated risk

\begin{tabular}{lcccc}
\hline Alternatives & Benefit & Cost & $\begin{array}{c}\text { Benefit/ } \\
\text { Cost } \\
\text { Ratio }\end{array}$ & Risk \\
\hline $\begin{array}{l}\text { Catalytic gas } \\
\text { Detector (A1) }\end{array}$ & 0.1244 & 0.1585 & 0.7849 & $\begin{array}{c}0.1654 \\
\text { (Tolerable) }\end{array}$ \\
$\begin{array}{l}\text { Open-path gas } \\
\text { Detector (A2) }\end{array}$ & 0.2242 & 0.2558 & 0.8765 & $\begin{array}{c}0.2815 \\
\text { (Tolerable) }\end{array}$ \\
$\begin{array}{l}\text { Point infrared } \\
\text { gas detector } \\
\text { (A3) }\end{array}$ & $\mathbf{0 . 3 0 5 6}$ & $\mathbf{0 . 1 8 4 3}$ & $\mathbf{1 . 6 5 8 2}$ & $\begin{array}{c}\mathbf{0 . 0 5 7 4} \\
\text { (Acceptable) }\end{array}$ \\
$\begin{array}{l}\text { Ultrasonic gas } \\
\text { Leak detector } \\
\text { (A4) }\end{array}$ & 0.2998 & 0.4015 & 0.7467 & (Tolerable) \\
\hline
\end{tabular}




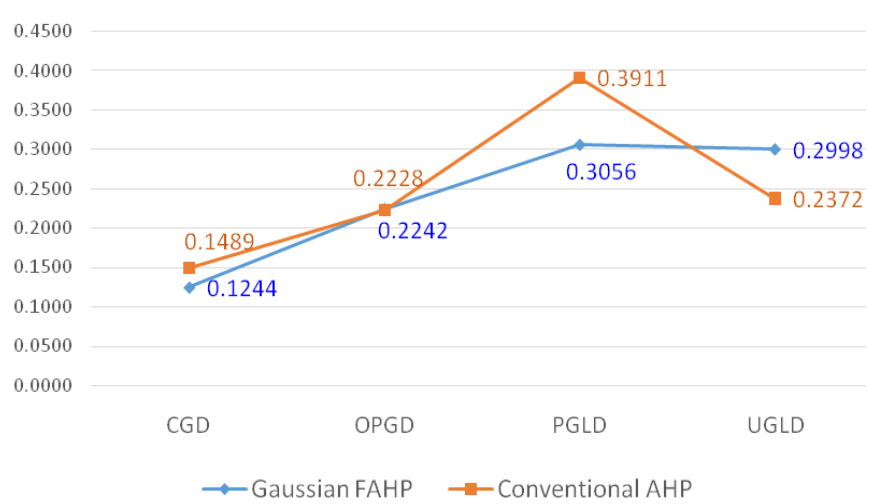

Figure 8 Alternatives final value comparison between Gaussian FAHP and conventional AHP for Benefit criteria

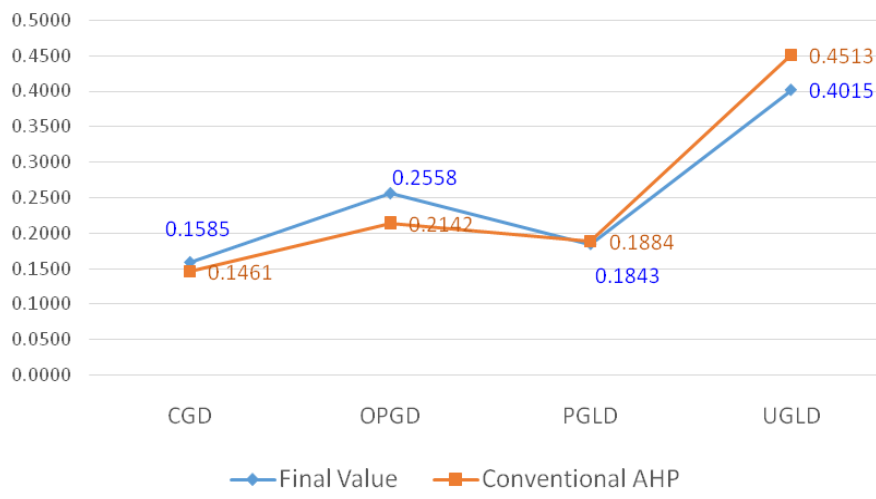

Figure 9 Alternatives final value comparison between Gaussian FAHP and conventional AHP for Cost criteria

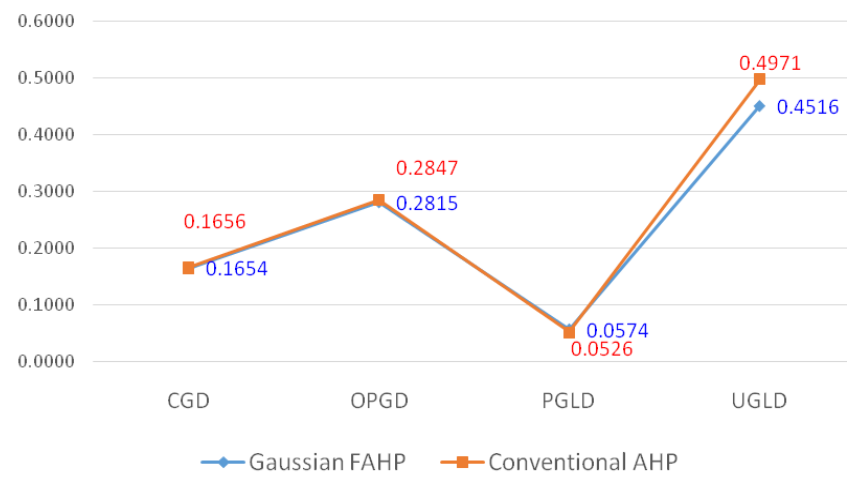

Figure 10 Alternatives final value comparison between Gaussian FAHP and conventional AHP for Risk criteria

\subsubsection{Sensitivity Analysis}

It is necessary to perform such a sensitivity analysis to evaluate how input change could lead to output difference. This means that if we perform a change in the input by adding or lowering the sub-criteria values, how far the expected output values in the alternatives will change. The sensitivity analysis is performed by changing the rank of importance of benefit, cost, and risk sub-criteria. For instance, we change the least important sub-criteria to become the most important sub-criteria. This analysis foresees if the alternative output value remains same or it may change. The sensitivity analysis foresees if there is a change on the expert panelists or the OGPA management's perspective in regards to sub-criteria weight, the alternatives ranking remains same. Descriptive graphics and chart in Figure 11 until Figure 13 is displayed as the result of the sensitivity analysis.

Based on calculation in chapter 3, the most significant sub-criterion is reliability and precision followed by delivering continuous concentration; whereas the least significant sub-criterion is response time followed by oxygen deficiency resistance. The sensitivity analysis is performed by lowering 50\% weight of reliability and precision as well as delivering continuous concentration sub-criteria. It is also performed an addition of $50 \%$ weight to the least significant sub-criteria, response time and oxygen deficiency resistance. Figure 5 describes the result of sensitivity analysis.

It is observed that there is no ranking change of alternatives. The result is still consistent, revealing that point infrared gas detector still the most beneficial gas detector technology, and catalytic gas detector brings the least beneficial gas detector technology.

The similar method of sensitivity analysis is implemented for Cost criteria. The most significant factor in Cost criteria, capital expenditure of the technology and preventive maintenance cost are lowered by $50 \%$. Similarly, as the least significant subcriteria, training and development cost and breakdown maintenance cost are added by $50 \%$ weight. The result of sensitivity analysis for Cost criteria confirms that the ranking of alternatives does not change. The ranking structure is consistent, following the values of each alternative.

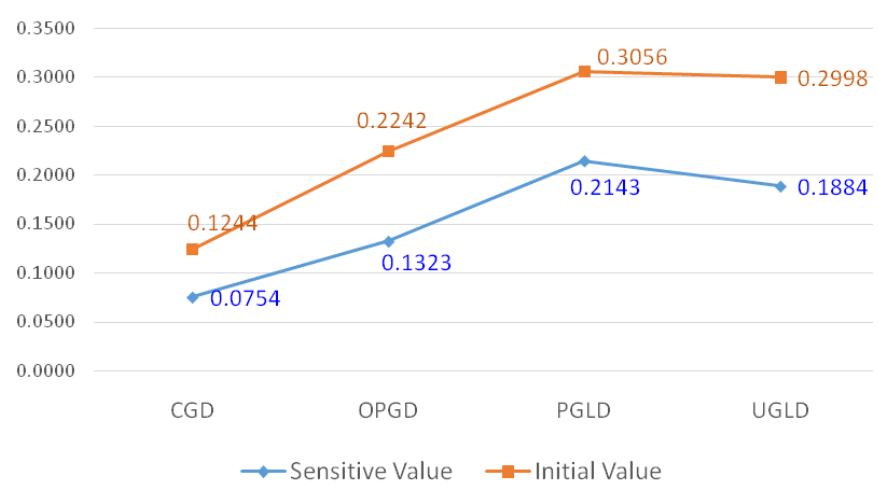

Figure 11 The result of sensitivity analysis for benefit criteria 


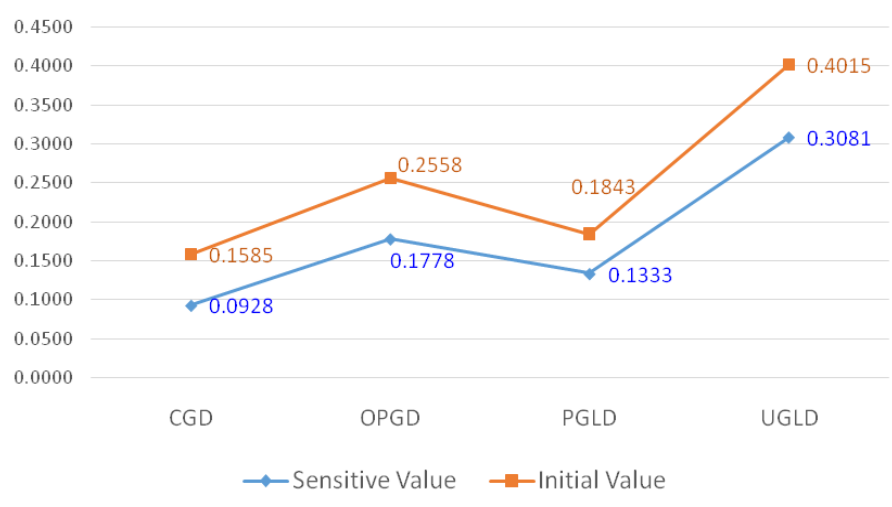

Figure 12 The result of sensitivity analysis for cost criteria

Lastly, the sensitivity analysis is performed for Risk criteria. We perform weight reduction to the most significant sub-criteria by $50 \%$ and addition for the least significant sub-criteria by $50 \%$. Consistent result is also obtained for risk criteria. The alternatives ranking position remains same with those in the initial Gaussian FAHP. Based on the result of sensitivity analysis, it is confirmed that the alternatives rank position does not change in spite of sub-criteria weight change for all criteria. Therefore, the evaluation of this research is able to a give consistent guidance to select the gas detector technology.

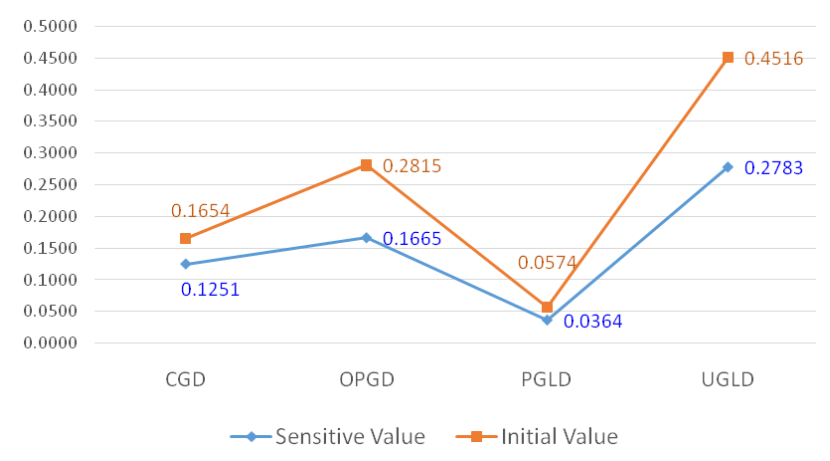

Figure 13 The result of sensitivity analysis for risk criteria

\subsection{CONCLUSION}

In terms of benefit criteria, point infrared gas detector brings more advantages compared to the other gas detectors. Those values rely upon its capability of delivering accurate monitoring, less spurious detection and quick response time. In contrary, catalytic gas detector brings the least value of benefit due to incapability of working in oxygen deficiency. In regards to the cost criteria, the ultrasonic leak detector shows the largest values because its technology possesses a larger amount of cost, with respect to capital expenditures, breakdown maintenance cost, and training cost. The evaluation of risk criteria shows point infrared gas detector is the least risk gas detector among other types of gas detector technology.

The Gaussian FAHP analysis for benefit, cost, and risk analysis reveals that point infrared gas detector has the highest score (1.6582). This means that point infrared technology has efficient value in delivering service to the process safety operation. Point infrared gas detector also reveals the best value in risk category analysis, which means the technology is capable of delivering reliable safety system. The methodology involved in the research, integration of Delphi technique and Gaussian FAHP, provides scientific guidance for gas detector technology selection. Concisely, the Gaussian FAHP analysis would lead the management to select which technology is best applied in OGPA.

\section{Acknowledgement}

This research is conducted at the oil and gas processing area operated by the Petroleum Company in East Kalimantan, Indonesia. The authors would like to express gratitude to the expert panelists and the OGPA's workers involving in Delphi technique for developing the criteria and subcriteria.

\section{References}

[1] Mannan, S. 2012. Lee's Loss Prevention in the Process Industries. Fourth Edition. Elsevier, USA. DOI: https://doi.org/10.1016/B978-0-12-397189-0.00001-X.

[2] Legg, S. W. 2013. Stochastic Programming Approaches for the Placement of Gas Detectors in Process Facilities. (August). Available
http://oaktrust.library.tamu.edu/handle/1969.1/150991.

[3] Dalkey, N., and Helmer, O. 1963. An Experimental Application of the Delphi Method to the Use of Experts. United States Air Force Project RAND, Copyright 1963 by INFORMS. Santa Monica. California. 458-467. DOI: http://doi.org/10.1287/mnsc.9.3.458.

[4] Hwang, C. -L., and Lin, M. -J. 2012. Group Decision Making Under Multiple Criteria: Methods and Applications. Vol. 281. Springer, USA.

[5] Zangenehmadar, Z., and Moselhi, O. 2016. Prioritizing Deterioration Factors of Water Pipelines using Delphi Method. Measurement: Journal of the International Measurement Confederation. 90: 491-499. DOI: https://doi.org/10.1016/j.measurement.2016.05.001.

[6] Reza, M., Yilmaz, O., Reza, Y., Mohammad, A., and Seyed, M. H. 2013. Ranking the Sawability of Ornamental Stone Using Fuzzy Delphi and Multi-criteria Decision-making Techniques. International Journal of Rock Mechanics and Mining Sciences. 58: 118-126.

DOI: https://doi.org/10.1016/j.jirmms.2012.09.002.

[7] Ouyang, X. and Guo, F. 2018. Intuitionistic Fuzzy Analytical Hierarchical Processes for Selecting the Paradigms of Mangroves in Municipal Wastewater Treatment. Chemosphere. 197: 634-642.

DOI: https://doi.org/10.1016/j.chemosphere.2017.12.102.

[8] Qiu, M., Shi, L., Teng, C., and Zhou, T. 2017. Assessment of Water Inrush Risk Using the Fuzzy Delphi Analytic Hierarchy Process and Grey Relational Analysis in the Liangzhuang Coal Mine, China. Mine Water and the Environment. 36(1): 39-50. DOI: https://doi.org/10.1007/s10230-016-0391-7. 
[9] Wu, H. -Y., Wu, H. -S., Chen, I. -S, Chen, H. -C. 2014. Exploring The Critical Influential Factors of Creativity For College Students: A Multiple Criteria Decision-making Approach. Thinking Skills and Creativity. 11 (2014): 1-21. DOI: https://doi.org/10.1016/j.tsc.2013.09.004.

[10] Zhu, K. 2014. Fuzzy Analytic Hierarchy Process: Fallacy of the Popular Methods. European Journal of Operational Research. 236: 209-217 DOI: https://doi.org/10.1016/j.ejor.2013.10.034.

[11] Sirisawat, P., and Kiatcharoenpol, T. 2018. Fuzzy AHPTOPSIS Approaches to Prioritizing Solutions for Reverse Logistics Barriers. Computers \& Industrial Engineering. 117: 303-318. DOI: https://doi.org/10.1016/j.cie.2018.01.015.

[12] Ho, W., and Ma, X. 2018. The State-of-the-art Integrtions and Applications of the Analytic Hierarchy Process. European Journal of Operational Research. 267: 399-414 DOI : https://doi.org/10.1016/j.ejor.2017.09.007.

[13] Shapiro, A. F., and Koissi, M. -C. 2017. Fuzzy Logic Modifications of the Analytic Hierarchy Process. Insurance: Mathematics and Economics. 75: 189-202 DOI: https://doi.org/10.1016/j.insmatheco.2017.05.003.

[14] Mardani, A., Jusoh, A., and Zavadskas, E. K. 2015. Fuzzy Multiple Criteria Decision-making Techniques and Applications - Two Decades Review From 1994 to 2014. Expert Systems with Applications. 42: 4126-4148 DOI: https://doi.org/10.1016/j.eswa.2015.01.003.

[15] Kaya, I,. Çolak, M., and Terzi, F. 2019. A Comprehensive Review of Fuzzy Multi Criteria Decision Making Methodologies for Energy Policy Making. Energy Strategy Reviews. 24: 207-228. DOI: https://doi.org/10.1016/j.esr.2019.03.003

[16] Xu, Z. 2014. Intuitionistic Fuzzy Analytic Hierarchy Process. IEEE Transcations on Fuzzy Systems. 22(4): 749-761 DOI: 10.1109/TFUZZ.2013.2272585

[17] Hefny, H. A., Elsayed, H. M., and Aly, H. F. 2013. Fuzzy Multicriteria Decision Making Model for Different Scenarios of Electrical Power Generation in Egypt. Egyptian Informatics Journal. 14(2): 125-133 DOI: http://dx.doi.org/10.1016/j.eij.2013.04.001

[18] Sahin, B., and Yip, T. S. 2017. SHipping Technology Selection for Dynamic Capability Based on improved Gaussian Fuzzy AHP Model. Ocean Engineering. 136: 233242. DOI : https://doi.org/10.1016/j.oceaneng.2017.03.032.

[19] Legg, S. W., Wang, C., Benavides-Serrano, A. J., and Laird, C. D. 2012. Optimal Gas Detector Placement under Uncertainty Considering Conditional-Value-at-Risk. Journal of Loss Prevention in the Process Industries. 26(3): 410-417. DOI: https://doi.org/10.1016/j.jp.2012.06.006.

[20] Naranjo, E., and Baliga, S. 2012. Early Detection of Combustible Gas Leaks Using Open-path Infrared (IR) Gas
Detectors. Proceedings of SPIE, 8366 (Advanced Environmental. Chemical, and Biological Sensing Technologies (IX). 83660V/1-83660V/6.

[21] Naranjo, E., and Baligha, S. 2009. Expanding the Use of Ultrasonic Gas Leak Detectors: A Review of Gas Release Characteristics for Adequate Detection. Gases and Instrumentation. (November/December): 24-29.

[22] Sizeland, E. 2014. Ultrasonic Devices Improve Gas Leak Detection in Challenging Environments, World Oil. (October): 133-135.

[23] Black, N., Murphy, M., Lamping, D., McKee, M., Sanderson, C., Ashkam, J., and Marteau, T. 1999. Consensus Development Methods: A Review of Best Practice in Creating Clinical Guidelines. Social Science Citation Index Journal of Health Services Research \& Policy. 4(4): 236-248. DOI: http://doi.org/10.1177/135581969900400410.

[24] Zadeh, L. A. 1965. Fuzzy Sets. Information and Control. 8(3): 338-353. DOI: https://doi.org/10.1016/S0019-9958(65)90241$\mathrm{X}$

[25] Zimmermann, H. J. 2001. Fuzzy Set Theory - and Its Applications. Fourth Edition. New York: Springer Science+Business Media, LLC.

[26] Laarhoven, P. J. M., and Pedrycz, W. 1983. A Fuzzy Extension of Saaty's Priority Theory. Fuzzy Sets, and Systems. $11(1-3): 229-241$. DOI: http://doi.org/10.1016/S0165-0114(83)80082-7.

[27] Zimmermann, H. -J. 2012. Fuzzy Sets, Decision Making, and Expert Systems. Vol. 10. Springer Science \& Business Media, USA.

[28] Sadi-Nezhad, S., and Damghani, K. K. 2010. Application of a Fuzzy TOPSIS Method Based on Modified Preference Ratio and Fuzzy Distance Measurement in Assessment of Traffic Police Centers Performance. Applied Soft Computing. 10: 1028-1039. DOI: http://doi.org/10.1016/j.asoc.2009.08.036

[29] Zhu, K. 2014. Fuzzy Analytic Hierarchy Process: Fallacy of the Popular Methods. European Journal of Operational Research. 236(1): 209-217 DOI: https://doi.org/10.1016/j.ejor.2013.10.034.

[30] Jing, L., Chen, B., Zhang, B., \& Peng, H. 2013. A Hybrid Fuzzy Stochastic Analytical Hierarchy Process (FSAHP) Approach for Evaluating Ballast Water Treatment Technologies. Environmental Systems Research. 2(10): 110. DOI: https://doi.org/10.1186/2193-2697-2-10.

[31] Zheng, G., Zhu, N., Tian, Z., Chen, Y., and Sun, B. 2011. Application of a Trapezoidal Fuzzy AHP Method for Work Safety Evaluation and Early Warning Rating of $\mathrm{Hot}$ and Humid Environments. Safety Science. 50(2): 228-239. DOI: https://doi.org/10.1016/j.ssci.201 1.08.042. 